Einführung

in die

Literaturwissenschaft 


\title{
EINFÜHRUNG IN DIE
}

\section{LITERATURWISSENSCHAFT}

\author{
herausgegeben von \\ Miltos Pechlivanos, Stefan Rieger \\ Wolfgang Struck und Michael Weitz
}

VERLAG J.B. METZLER

STUTTGART · WEIMAR 
Die Deutsche Bibliothek - CIP-Einheitsaufnahme

Einführung in die Literaturwissenschaft

hrsg. von Miltos Pechlivanos ... - Stuttgart ; Weimar : Metzler, 1995

ISBN 978-3-476-01225-8

NE: Pechlivanos, Miltos [Hrsg.]

ISBN 978-3-476-01225-8

ISBN 978-3-476-03544-8 (eBook)

DOI $10.1007 / 978-3-476-03544-8$

Dieses Werk einschließlich aller seiner Teile ist urheberrechtlich geschützt. Jede Verwertung außerhalb der engen Grenzen des Urheberrechtsgesetzes ist ohne Zustimmung des Verlages unzulässig und strafbar. Das gilt insbesondere für Vervielfältigungen, Übersetzungen, Mikroverfilmungen und die Einspeicherung und Verarbeitung in elektronischen Systemen.

(C) 1995 Springer-Verlag GmbH Deutschland

Ursprünglich erschienen bei J.B. Metzlersche Verlagsbuchhandlung

und Carl Ernst Poeschel Verlag GmbH in Stuttgart 1995 


\section{Inhaltsverzeichnis}

Grenzziehungen

Seite 1

I. Aufzeichnungsmodelle

Seite

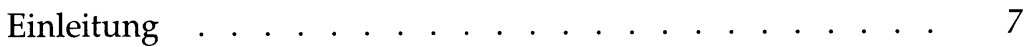

Dagmar Buchwald: Buchstabe, Schriftbild, Bild als Schrift . . 11

Gesine Lübben: Exkurs: Mündlichkeit - Schriftlichkeit . . . . 23

Rudolf Helmstetter: Lyrische Verfahren:

Lyrik, Gedicht und poetische Sprache _ . . . . . . . . 27

Holt Meyer: Exkurs: Formalismus und Strukturalismus . . . 43

Reinhold Schardt: Narrative Verfahren . . . . . . . . . . . 49

Holt Meyer: Gattung . . . . . . . . . . . . . . . . . . . 66

Wolfgang Struck: Exkurs: Drama und Theater _ . . . . . . 78

Uwe Hebekus: Topik/Inventio . . . . . . . . . . . . . . . . 82

Elias Torra: Rhetorik . . . . . . . . . . . . . . . . . . . 97

Elias Torra: Exkurs: Stilistik _. . . . . . . . . . . . . . 112

Bettine Menke: Dekonstruktion. Lesen, Schrift, Figur, Performanz 116

II. Vermittlungsmodelle

Seite 139

Einleitung . . . . . . . . . . . . . . . . . . . . . . 141

Stefan Rieger: Autorfunktion und Buchmarkt . . . . . . . . 147

Stefan Rieger: Exkurs: Diskursanalyse . . . . . . . . . . . 164

Miltos Pechlivanos: Literaturgeschichte(n) _ . . . . . . . . 170

Wolfgang Struck: Soziale Funktion und kultureller Status

literarischer Texte oder: Autonomie als Heteronomie. . . . 182 Aleida und Jan Assmann: Exkurs:

Archäologie der literarischen Kommunikation . . . . . . 200 Shankar Raman/Wolfgang Struck: Ideologie und ihre Kritiker . 207 Renate Lachmann: Exkurs: Anmerkungen zur Phantastik . . . 224 Gabriele Rippl: Feministische Literaturwissenschaft . . . . . 230 Shankar Raman: The Racial Turn: >Race`, Postkolonialität,

Literaturwissenschaft . . . . . . . . . . . . . . . . . 241

Neil Roughley: Begriffe und Anschauungen oder:

Wozu noch Ästhetik? . . . . . . . . . . . . . . . . . 256

Jana Ziganke: Exkurs: Literaturkritik . . . . . . . . . . . 271 


\section{III. Übersetzungsmodelle}

Einleitung . . . . . . . . . . . . . . . . . 279

Almut Finck: Subjektbegriff und Autorschaft:

Zur Theorie und Geschichte der Autobiographie . . . . . 283

Ulla Haselstein: Exkurs: Psychoanalyse und Literaturwissenschaft . . . . . . . . . . . . . 295

Eva Horn: Subjektivität in der Lyrik:

`Erlebnis und Dichtung<, >lyrisches Ichく . . . . . . . . . 299

Dagmar Buchwald: Intentionalität, Wahrnehmung,

Vorstellung, Un-Bestimmtheit . . . . . . . . . . . . . 311

Joachim Jacob: Verstehen konstruieren . . . . . . . . . . . 324

Joachim Jacob: Exkurs: Literarische Hermeneutik . . . . . . . 337

Hans-Walter Schmidt: Kulturspezifische Lektüren:

Interkulturelle Hermeneutik oder Ethnographie des Lesens? 340

Markus Krist: Exkurs: Aufzeichnung und Entgrenzung

kultureller Alterität. Topik der Reiseberichte und

Rousseaus zweiter Discours . . . . . . . . . . . . . . 347

Michael Weitz: Zur Karriere des Close Reading:

New Criticism, Werkästhetik und Dekonstruktion . . . . 354

Schamma Schahadat: Intertextualität: Lektüre - Text - Intertext 366

Stefan Rieger: Memoria und Oblivio.

Die Aufzeichnung des Menschen . . . . . . . . . . . . 378

\section{Entgrenzungen}

Wolfgang Struck: Medienwelten

Stefan Rieger: Medienwissenschaft der Literatur -

Literaturwissenschaft der Medien . . . . . . . . . . . . . 402

Literaturverzeichnis . . . . . . . . . . . . . . . 413

Personenregister . . . . . . . . . . . . . . . . . 440

Sachregister . . . . . . . . . . . . . . . . . . . 449 